\title{
Across the great divide
}

\author{
It is fifty years since science and the humanities were identified as "two cultures" between which \\ communication had all but ceased.
}

"A good many times I have been present at gatherings of people who, by the standards of the traditional culture, are thought highly educated and who have with considerable gusto been expressing their incredulity at the illiteracy of scientists. Once or twice I have been provoked and have asked the company how many of them could describe the Second Law of Thermodynamics. The response was cold: it was also negative. Yet I was asking something which is the scientific equivalent of: Have you read a work of Shakespeare's?

"I now believe that if I had asked an even simpler question - such as, What do you mean by mass, or acceleration, which is the scientific equivalent of saying, Can you read? - not more than one in ten of the highly educated would have felt that I was speaking the same language."

These words are taken from the Rede lecture, delivered on 7 May 1959 at the University of Cambridge, by the British novelist C. P. Snow. Snow's thesis was that a worrying gulf had opened between science and the humanities, that they were now polarized into what he called "the two cultures". Having trained and worked as a physicist before entering the civil service and writing his 'Strangers and Brothers' series of novels, Snow had moved in both circles and distilled the mood of the time into that succinct phrase, which still has currency.

To some extent, the problem that Snow had recognized was peculiar to Britain, specifically the Britain of the 1930s, when Snow had been a researcher at the Cavendish Laboratory in Cambridge. He recalled a remark made to him then by the mathematician G. H. Hardy: "Have you noticed how the word 'intellectual' is used nowadays? There seems to be a new definition which certainly doesn't include Rutherford or Eddington or Dirac or Adrian or me. It does seem rather odd, don't y'know." The status of 'intellectual' seemed suddenly to belong exclusively to the group that Snow preferred to label the 'literary intellectuals', and not to scientists.

The fissure had opened more than a century earlier, with the coming of the industrial revolution, and grew as the body of scientific knowledge developed.
By the 1830s, the word 'scientist' had been coined - by scientists - in counterpoint to 'artist', reflecting "the growth of a self-conscious sense of professional identity among those who studied the natural world"2. The scientists had declared themselves different from the traditional literary culture, which largely ignored them.

That the issue became so pronounced in Britain, Snow blamed on excessively specialized education. The British school system demanded a greater degree of specialization, restricting at a young age the number of subjects studied, than any other system in the Western world and, fifty years on, little has changed there. Broad education is, however, vital: increasing knowledge necessarily means increasing specialization (the times of knowing everything are past), but specialization is not necessarily a barrier to communication.

\section{Specialization is not necessarily a barrier to communication.}

Back in the 1950s, Snow cited the example of Chen-Ning Yang and Tsung-Dao Lee and their recent discovery of the non-conservation of parity. This "piece of work of the greatest beauty and originality", said Snow in his lecture, "...makes us think again about some of the fundamentals of the physical world. Intuition, common sense - they are neatly stood on their heads... If there were any serious communication between the two cultures, this experiment would have been talked about at every High Table in Cambridge." (To be fair, this works both ways: Snow also bemoans those scientists who "modestly confess, 'Well, I've tried a bit of Dickens', rather as though Dickens were an extraordinarily esoteric, tangled and dubiously rewarding writer".)

Although "the two cultures" is the sound bite that has entered history, the full title of Snow's lecture was The Two Cultures and the Scientific Revolution, and his perspective spread wider than the Cambridge high tables. Beyond the issue of the two cultures, and of societies governed mostly by those educated in the traditional literary culture, Snow was calling for recognition of the power of applying science to solve the world's problems. Admittedly, he rather overegged the pudding, predicting of the disparity between rich and poor that "Whatever else in the world we know survives to the year 2000, that won't." Snow's Utopian future would arise from the toil of a growing population of trained scientists and engineers, following through on the progress of the eighteenth-century industrial revolution and properly exploiting the science of the twentieth century.

It was never that simple, of course. Snow omitted any realistic consideration of world politics, the factor that would override any hope of eradicating poverty. This and other shortcomings in his reasoning left his lecture susceptible to criticism, which swiftly followed (including a famously vicious attack made by the literary critic F. R. Leavis, through the medium of the Richmond lecture at Cambridge in 1962). Snow responded with another treatise, The Two Cultures: $A$ Second Look, in 1963, concluding:

"The division of our culture is making us more obtuse than we need be: we can repair communications to some extent: but, as I have said before, we are not going to turn out men and women who understand as much of our world as Piero della Francesca did of his, or Pascal, or Goethe. With good fortune, however, we can educate a large proportion of our better minds so that they are not ignorant of imaginative experience, both in the arts and in science, nor ignorant neither of the endowments of applied science, of the remediable suffering of most of their fellow humans, and of the responsibilities which, once they are seen, cannot be denied."

Snow still held that the appreciation and application of science was the key to the future. Fifty years on, perhaps there is at last the political will to make that good.

\footnotetext{
References

1. Snow, C. P. The Two Cultures 14-15 (Cambridge Univ. Press, 1998)

2. Collini, S. in The Two Cultures xii (Cambridge Univ. Press, 1998).

3. Snow, C. P. The Two Cultures 53-100 (Cambridge Univ. Press, 1998)
} 